\title{
Decline in measles mortality: nutrition, age at infection, or exposure?
}

\author{
PETER AABY，JETTE BUKH， IDA MARIA LISSE， MARIA CLOTILDE DA SILVA
}

\begin{abstract}
The mortality from measles was studied in an urban area of Guinea-Bissau one year before and five years after the introduction of a vaccination programme. The years after the introduction of immunisation saw a decline in mortality among unvaccinated children with measles. This decline occurred despite a lower age at infection and an increasing prevalence of malnourished children. State of nutrition (weight for age) did not affect the outcome of measles infection. The incidence of isolated cases, however, increased in the period after the introduction of measles vaccination. As mortality was lower among these cases, diminished clustering explained some of the reduction in mortality. Comparison between the urban district and a rural area inhabited by the same ethnic group showed a lower age at infection, less clustering of cases, and lower case fatality ratios in the urban area.

Endemic transmission of measles in urban districts leads to less clustering of cases, which may help explain the usually lower case fatality ratios in these areas. As measles vaccination increases herd immunity and diminishes clustering of cases, it may reduce mortality even among unvaccinated children who contract the disease.
\end{abstract}

\section{Introduction}

The high mortality caused by measles virus in developing countries is usually attributed to malnutrition and young age at infection. ${ }^{1}$ The decline in mortality from measles, such as occurred in the industrialised world during the beginning of this century, has therefore been explained as a result of improved nutrition ${ }^{2}$ and increased age at infection. ${ }^{3}$ Recent community studies, however, have found no relation between premorbid state of nutrition and the subsequent risk of dying of measles. ${ }^{45}$ Instead, high mortality in severe epidemics of measles in Guinea-Bissau was associated with clustering of cases and the intensity of exposure in secondary cases in the household. ${ }^{67}$ This suggests that reduced clustering and diminished exposure may result in a decline in mortality from measles. We report on further community studies from GuineaBissau, which provided an opportunity to examine these contrasting hypotheses concerning the decline in mortality from measles.

\footnotetext{
Institute of Ethnology and Anthropology, University of Copenhagen, 1220 Copenhagen K, Denmark PETER AABY, MSC, lecturer JETTE BUKH, MSC, social science adviser

Department of Pathology, Hvidovre Hospital, Copenhagen, Denmark IDA MARIA LISSE, MD, registrar

MCH Programme, Ministry of Health, Bissau, Guinea-Bissau MARIA CLOTILDE DA SILVA, MD, director

Correspondence and requests for reprints to: $\mathrm{Mr}$ Aaby.
}

\section{Population and methods}

\section{MEASLES IN BANDIM}

The incidence of measles and mortality from the disease have been monitored in Bandim, an urban district in the capital of Guinea-Bissau, from the beginning of 1979 to the end of $1984 .{ }^{4}{ }^{10}$ Vaccinations were introduced in Bandim in January 1980 and the rate of coverage has been maintained at over $80 \%{ }^{9}$

Our study population consisted of all patients who had measles in Bandim between January 1979 and December 1984 as well as people registered in Bandim who contracted measles outside the district during the period. There was no difference in mortality between Bandim residents registered before the occurrence of measles and new residents or visitors registered during an attack of measles in Bandim. ${ }^{8}$ The follow up period has previously been divided into three subperiods: (a) January to December 1979-that is, preceding the introduction of measles immunisation ${ }^{46} ;(b)$ January 1980 to February $1982^{89}$; and $(c)$ March 1982 to May $1983 . .^{10}$ This study includes a fourth period with only few cases, from June 1983 to December 1984. Data on measles were collected as before. From the beginning of 1985 the Edmonston-Zagreb measles vaccine has been used in Bandim, which makes conditions unrepresentative. Data from this period are therefore excluded.

Death associated with measles was defined as any death occurring within a month of an attack of the disease. The diagnosis of measles was obtained from adult members of each household, usually the mother or grandmother. Both the high secondary attack rate ${ }^{68}$ and antibody studies ${ }^{10}$ suggest that lay people in Bissau usually diagnose measles correctly.

\section{VACCINATION STATE}

Children were considered to be immunised against measles if vaccination was recorded on their file card at the health centre or on an immunisation card held by the family. Immunisation was counted from three weeks after the date of vaccination.

\section{QUINHAMEL 1979-8I}

The population in Bandim is $60 \%$ Pepel. Measles was also studied in Quinhamel, a rural area whose population is $100 \%$ Pepel. $^{7}$ The data used for comparison with the urban setting pertain only to the period before vaccination was introduced (1979-81).

\section{STATE OF NUTRITION}

Children aged 0-35 months were weighed every three months in Bandim and every six months in Quinhamel. Only those weights obtained at the examination immediately preceding the attack of measles have been used in the statistics. Weight is expressed as a percentage of the National Center for Health Statistics. ${ }^{11}$ As many children who contracted measles in Bandim were previously unregistered new residents or visitors or had been away for long periods and never been vaccinated, weight measurements from the examination immediately preceding the attack of measles were available for only $143(51 \%)$ of the 281 children under 3 .

\section{CLUSTERING AND EXPOSURE}

The definition of clustering and exposure was based on the number of concurrent cases of measles and the likely source of infection. In Bandim several families may live in a single house. Cases of measles were classified as isolated when only one person in a household contracted the disease and there were no other cases in the house. In houses with several cases the first child who contracted measles was termed the index case. Children who became ill seven or more days after an index case were assumed to be secondary cases infected inside the house. ${ }^{4}$ 
In the rural area cases were classified as isolated when there was only one case in a compound.

\section{STATISTICAL METHODS}

The Mantel-Haenszel $\chi^{2}$ test and odds ratio were used to combine the results from the individual $2 \times 2$ tables corresponding to various age subgroups. ${ }^{12}$

\section{Results}

After the introduction of measles vaccination in Bandim the age pattern among unvaccinated cases diverged. On the one hand, the proportion of all patients aged 5 years or older increased from $22 \%$ (103/459) in 1979 to $29 \%$ $(100 / 342)$ in subsequent years $\left(p<0.05 ; \chi^{2}=4.8\right)$ (table I). On the other hand, because many of the older children had been vaccinated the proportion of younger patients also increased. For example, the proportion of patients aged under 2 increased from $37 \%(169 / 459)$ in 1979 to $47 \%(160 / 342)$ in 1980 4 (odds ratio $=1 \cdot 51,95 \%$ confidence interval $1 \cdot 14$ to $2 \cdot 01 ; \mathrm{p}<0.01 ; \chi^{2}=8 \cdot 0$ ). At the same time the proportion of children with measles aged under 3 and with low weight for age (below $80 \%$ of standard) increased from $16 \%$ (29/ 187 ) in 1979 to $23 \%(33 / 143$ ) in $1980-4$ (table II; odds ratio $=1.83,95 \%$ confidence interval 1.02 to $3 \cdot 27 ; \mathrm{p}<0.05$; Mantel-Haenszel $\chi^{2}=4 \cdot 2$ ).

TABLE I-Percentage mortality from measles stratified by age. Bandim 1979 and 1980-4. (Numbers of deaths/cases given in parentheses)

\begin{tabular}{cccc}
\hline & & \multicolumn{2}{c}{$1980-4$} \\
\cline { 3 - 4 } $\begin{array}{c}\text { Age } \\
\text { (years) }\end{array}$ & 1979 & Total & Unvaccinated \\
\hline$<1$ & $28(22 / 79)$ & $17(15 / 88)$ & $17(13 / 78)$ \\
1 & $26(23 / 90)$ & $10(12 / 122)$ & $12(10 / 82)$ \\
2 & $24(19 / 78)$ & $11(8 / 71)$ & $24(7 / 29)$ \\
$3-4$ & $9(10 / 109)$ & $8(7 / 86)$ & $8(4 / 53)$ \\
$5-9$ & $4(3 / 75)$ & $5(4 / 77)$ & $5(3 / 59)$ \\
$\geqslant 10$ & $0(0 / 28)$ & $10(48 / 485)$ & $11(39 / 342)$ \\
\hline Total & $17(77 / 459)$ & & \\
\hline
\end{tabular}

TABLE II-Prevalence of low weight for age $(<80 \%)$ stratified by age and period. Bandim 1979 and 1980-4. Figures are numbers of cases (percentages in parentheses) ${ }^{\star}$

\begin{tabular}{ccr}
\hline $\begin{array}{c}\text { Age } \\
\text { (months) }\end{array}$ & 1979 & $1980-4$ \\
\hline $0-11$ & $6 / 75(8 \cdot 0)$ & $13 / 66(19 \cdot 7)$ \\
$12-23$ & $11 / 59(18 \cdot 6)$ & $14 / 59(23 \cdot 7)$ \\
$24-35$ & $12 / 53(22 \cdot 6)$ & $6 / 18(33 \cdot 3)$ \\
\hline Total & $29 / 187(15 \cdot 5)$ & $33 / 143(23 \cdot 1)$ \\
\hline
\end{tabular}

$\star$ Weights obtained at examination immediately preceding (0-3 months) attack of measles.

Despite these tendencies the mortality from measles declined from $17 \%$ in 1979 to $10 \%$ in subsequent years (table I). Vaccinated childen had a lower mortality than unvaccinated. ${ }^{8}$ Even when only unvaccinated children under 5 were considered, however, mortality from measles declined from $21 \%$ (74/ 356 ) to $14 \%(34 / 242$ ) over the same period (table I; odds ratio $=0.58,95 \%$ confidence interval 0.37 to $0.91 ; p<0.05 ;$ Mantel-Haenszel $\left.\chi^{2}=5.7\right)$. Table I shows that the decline in mortality was confined to children aged under 2 .

In line with other reports from this community ${ }^{4}$ there was no relation between weight for age at the examination immediately preceding the attack of measles and the subsequent risk of dying of the infection (table III).

The lower age at infection in the community was due to prior immunity from infection or immunisation of most of the older children. Younger children were therefore less likely to be infected simultaneously with an older sibling. The incidence of isolated cases thus increased significantly from $16 \%(47 / 290)$ in 1979 to $33 \%(21 / 63)$ in $1980-2$ (table IV; odds ratio= $2.52,95 \%$ confidence interval 1.37 to $4.64 ; \mathrm{p}<0.005$; Mantel-Haenszel $\chi^{2}=8.9$ ) and to $28 \%(41 / 147)$ in $1982-4$ (table IV; odds ratio $=1.91$, $95 \%$ confidence interval $1 \cdot 17$ to $3 \cdot 12 ; \mathrm{p}<0 \cdot 01$; Mantel-Haenszel $\chi^{2}=6 \cdot 7$ ).

In all periods age specific case fatality ratios were much lower among isolated cases than among secondary cases (table IV)-1979: odds ratio= $0 \cdot 13,95 \%$ confidence interval 0.04 to $0.43, \mathrm{p}<0.001$, Mantel-Haenszel $\chi^{2}=$ $11 \cdot 1 ; 1980-2$ : odds ratio not defined, $\mathrm{p}<0.005$, Mantel-Haenszel $\chi^{2}=9.5$; 1982-4: odds ratio $=0.09,95 \%$ confidence interval 0.02 to $0.53, \mathrm{p}<0.01$, Mantel-Haenszel $\chi^{2}=7 \cdot 1$.

TABLE III-Case fatality ratio of measles infection stratified by weight for age before infection and immunisation state. Bandim 1980-4. Figures are numbers of cases (percentages in parentheses)

\begin{tabular}{cccc}
\hline $\begin{array}{c}\text { Weight for age } \\
\text { (\% of standard) }\end{array}$ & $\begin{array}{l}\text { Not vaccinated } \\
\text { against measles }\end{array}$ & $\begin{array}{c}\text { Vaccinated } \\
\text { against measles }\end{array}$ & Total \\
\hline \multicolumn{4}{c}{ Age group 0-11 months } \\
$58-69$ & $0 / 2$ (17) & $0 / 1$ & $0 / 3$ \\
$70-79$ & $1 / 6(19(16)$ & $1 / 4(25)$ & $2 / 10(20)$ \\
$80-99$ & $1 / 21(5)$ & $0 / 12(25)$ & $6 / 31(19)$ \\
$\geqslant 100$ & Age group 12-35 months & $1 / 22(5)$ \\
& $0 / 2$ & $0 / 2$ & \\
$60-69$ & $1 / 6(17)$ & $0 / 10$ & $1 / 4$ \\
$70-79$ & $2 / 17(12)$ & $0 / 29$ & $2 / 46(4)$ \\
$80-99$ & $2 / 3(67)$ & $1 / 8(13)$ & $3 / 11(27)$ \\
$\geqslant 100$ & All ages (0-35 months) & & \\
& $0 / 4$ & $0 / 3$ & $0 / 7$ \\
$58-69$ & $2 / 12(17)$ & $1 / 14(7)$ & $3 / 26(12)$ \\
$70-79$ & $5 / 36(14)$ & $3 / 41(7)$ & $8 / 77(10)$ \\
$80-99$ & $3 / 24(13)$ & $1 / 9(11)$ & $4 / 33(12)$ \\
\hline 100 & & & \\
\hline
\end{tabular}

By using the 1979 age specific case fatality ratios for all cases the expected number of deaths in $1980-4$ was calculated as $44 \cdot 1$ (table IV) compared with 40.5 expected when the case fatality ratios of isolated, index, and secondary cases in 1979 were used as the basis. The difference was due to the change in clustering and exposure in $1980-4$ in relation to 1979 . Thus $22 \%(3 \cdot 6 / 16 \cdot 1)$ of the reduction in mortality may in this instance have been due to changes in clustering. The remaining reduction in mortality must be ascribed to diminished severity of cases, and particularly to a diminished case fatality ratio among secondary cases in 1982-4. Between 1979 and 1980-2 there was no change in the general severity of cases (table IV).

TABLE IV-Percentage mortality from measles stratified by age and exposure. Unvaccinated children only. Bandim 1979-84. (Numbers of deaths/cases given in parentheses) ${ }^{\star}$

\begin{tabular}{|c|c|c|c|c|}
\hline $\begin{array}{c}\text { Age } \\
\text { (years) }\end{array}$ & $\begin{array}{l}\text { Isolated } \\
\text { cases }\end{array}$ & $\begin{array}{l}\text { Index } \\
\text { cases }\end{array}$ & $\begin{array}{l}\text { Secondary } \\
\text { cases }\end{array}$ & Total \\
\hline $\begin{array}{c}<1 \\
1 \\
2 \\
3-4\end{array}$ & $\begin{array}{c}13(1 / 8) \\
11(2 / 19) \\
0(0 / 10) \\
0(0 / 10)\end{array}$ & $\begin{array}{l}1979 \\
0(0 / 15) \\
21(3 / 14) \\
14(2 / 14) \\
5(2 / 38)\end{array}$ & $\begin{array}{l}35(15 / 43) \\
33(14 / 43) \\
38(14 / 37) \\
13(5 / 39)\end{array}$ & $\begin{array}{c}24(16 / 66) \\
25(19 / 76) \\
26(16 / 61) \\
8(7 / 87)\end{array}$ \\
\hline Total & $6(3 / 47)$ & $9(7 / 81)$ & $30(48 / 162)$ & $20(58 / 290)$ \\
\hline $\begin{array}{l}<1 \\
1 \\
2 \\
3-4\end{array}$ & $\begin{array}{l}0(0 / 5) \\
0(0 / 9) \\
0(0 / 2) \\
0(0 / 5)\end{array}$ & $\begin{array}{c}1980-2 \\
0(0 / 4) \\
0(0 / 4) \\
50(1 / 2) \\
0(0 / 6)\end{array}$ & $\begin{array}{l}63(5 / 8) \\
22(2 / 9) \\
50(1 / 2) \\
29(2 / 7)\end{array}$ & $\begin{array}{c}29(5 / 17) \\
9(2 / 22) \\
33(2 / 6) \\
11(2 / 18)\end{array}$ \\
\hline $\begin{array}{l}\text { Total } \\
\text { Expected deaths } \dagger\end{array}$ & $\begin{array}{l}0(0 / 21) \\
1.5\end{array}$ & $\begin{array}{l}6(1 / 16) \\
1 \cdot 5\end{array}$ & $\begin{array}{l}38(10 / 26) \\
7 \cdot 4\end{array}$ & $\begin{array}{l}17(11 / 63) \\
12 \cdot 6\end{array}$ \\
\hline $\begin{array}{l}<1 \\
1 \\
2 \\
3-4\end{array}$ & $\begin{array}{l}0(0 / 14) \\
5(1 / 19) \\
0(0 / 5) \\
0(0 / 3)\end{array}$ & $\begin{array}{c}1982-4 \\
0(0 / 6) \\
0(0 / 6) \\
25(1 / 4) \\
11(1 / 9)\end{array}$ & $\begin{array}{c}16(5 / 32) \\
21(5 / 24) \\
43(3 / 7) \\
6(1 / 18)\end{array}$ & $\begin{array}{c}10(5 / 52) \\
12(6 / 49) \\
25(4 / 16) \\
7(2 / 30)\end{array}$ \\
\hline $\begin{array}{l}\text { Total } \\
\text { Expected deaths } \dagger\end{array}$ & $\begin{array}{l}2(1 / 41) \\
3 \cdot 8\end{array}$ & $\begin{array}{l}8(2 / 25) \\
2 \cdot 4\end{array}$ & $\begin{array}{l}17(14 / 81) \\
23.9\end{array}$ & $\begin{array}{l}12(17 / 147) \\
31 \cdot 5\end{array}$ \\
\hline
\end{tabular}

^Figures may differ from other reports ${ }^{6810}$ because table includes only unvaccinated Bandim residents and new residents or visitors.

†Expected deaths based on age specific case fatality ratios from 1979 epidemic.

The contrast between measles epidemics in urban and rural areas was examined in light of the divergent hypotheses. In Guinea-Bissau the Pepel ethnic group has been studied in both urban ${ }^{46}$ and rural settings. ${ }^{7}$ Before the introduction of vaccination age at infection was significantly lower in the urban area (table V; $p<0.001 ; \chi^{2}=12 \cdot 6$ ). Nevertheless, as there were 
significantly more isolated cases in the urban than rural area, there was less clustering of cases $\left(p<0.01 ; \chi^{2}=8.6\right)$. There was also a definite tendency towards lower mortality in the urban area $\left(p<0.05 ; \chi^{2}=4.7\right)$.

TABLE V-Measles epidemiology in rural and urban area (Quinhamel 1979-81, Bandim 1979). ${ }^{\star}$ Except where stated otherwise figures are percentages (whole numbers in parentheses)

\begin{tabular}{|c|c|c|c|}
\hline & $\underset{\text { (rural) }}{\text { Quinhamel }}$ & $\begin{array}{l}\text { Bandim } \\
\text { (urban) }\end{array}$ & $\begin{array}{l}\text { Odds ratio [ } 95 \% \\
\text { confidence } \\
\text { interval] }\end{array}$ \\
\hline \multicolumn{3}{|l|}{ Cases in children aged } & $1.9[1.4$ to 2.8$]$ \\
\hline \multicolumn{3}{|l|}{ Patients with weight } & $0.7[0.3$ \\
\hline Isolated casest & $2(1 / 57)$ & $17(37 / 222)$ & $11 \cdot 2[2 \cdot 2$ to $56 \cdot 5]$ \\
\hline \multicolumn{4}{|l|}{ Case fatality ratios: } \\
\hline Age $0-2$ years & $40(24 / 60)$ & $26(64 / 247)$ & $0.5[0.3$ to 0.9$]$ \\
\hline All ages & $24(38 / 160)$ & $17(77 / 459)$ & $0.7[0.4$ to 1.0$]$ \\
\hline
\end{tabular}

^Ethnic composition of Bandim 60\% Pepel and Quinhamel 100\% Pepel. Data in both instances refer to period before measles immunisation.

tChildren aged $0-2$ years.

\section{Discussion}

These data show that clustering of cases and intensity of exposure are more important determinants of the severity of measles than state of nutrition or age at infection in the community. Malnutrition has traditionally been assumed to be the main determinant of mortality from measles, ${ }^{13}$ improved nutrition therefore serving to explain the fall in mortality from measles which has occurred in the industrialised world over the past 100 years. ${ }^{2}$ Community studies from developing countries, however, show that state of nutrition does not determine the outcome of measles infection. ${ }^{47} 7^{14}$ is Though severely malnourished children may have a higher case fatality ratio than other children, ${ }^{16}$ no community study has been conclusive.${ }^{15}$ In Bandim there were virtually no severely malnourished children; hence extreme malnutrition cannot explain the high case fatality ratio found there. Both nutritional state and mortality decreased in Bandim during the period of observation (1979 to 1980-4).

Because of the inverse relation between age and severity of infection within a community it has been suggested that age at infection is an important determinant of mortality in the community. ${ }^{17}$ This emphasis on age at infection is clearly not supported by data from Bandim, where age at infection and case fatality fell simultaneously; nor from Quinhamel, where there was both a high median age at infection and a high case fatality ratio.

Variation in mortality in Guinea-Bissau is better explained by changes in clustering of cases. Isolated cases had a much lower case fatality ratio than secondary cases throughout the study period. As the incidence of isolated cases of measles increased in Bandim, part of the decline in mortality may be attributed to reduced clustering.

Other factors also contributed to the decline in mortality. Case fatality ratios did not change between 1979 and 1980-2, and only in 1982-4 did the ratio decline. The same level of preventive and curative services was available in Bandim throughout 1980-4. This together with the deterioration in state of nutrition and the stable case fatality ratios among children aged 2-4 years (table IV) makes it less likely that general environmental changes or improvements in medical services helped appreciably to reduce mortality. Hence there is no apparent explanation for the fall in case fatality ratio that occurred among secondary cases in children aged under 2 in 1982-4. Cases in vaccinated children are associated with lower mortality, and measles vaccinations became more frequent in Bandim during 1981-2. Some Bandim children and new residents or visitors may have had undocumented vaccinations at neighbouring health centres or at the central maternal and child health clinic in Bissau.

Observations from Bandim and Quinhamel suggest that changes in clustering and the intensity of exposure may be important in the variation in mortality from measles. In contrast with the age hypothesis nearly all community studies have shown a high median age at infection in rural areas and that this is associated with high mortality from the disease. ${ }^{5}$ From the clustering perspective, however, this is not a contradiction. The interval between epidemics affects the number of susceptible members in a family. In endemic settings there is a high likelihood that other siblings are already immune when measles is introduced in the family. With an increasing interval between epidemics more people are likely to be susceptible simultaneously, which will tend to increase the number of multiple cases and the risk of intensive exposure. This may increase the age specific case fatality ratio. Many factors, including less access to medical care, may contribute to higher mortality in rural areas. Nevertheless, mortality is higher among clusters of cases than in isolated or single cases in both rural ${ }^{7}$ and urban areas. ${ }^{6}$ Hence the higher mortality reported in virtually all rural epidemics compared with urban outbreaks of measles ${ }^{5}$ is probably related to the greater degree of clustering in rural zones.

The clustering and exposure hypothesis also suggests that measles immunisation may have unexpected effects on mortality. Measles vaccination reduces the concurrence of cases because some children have already been immunised before measles is introduced in a given household. By reducing the clustering of cases vaccination should lower the risk of intensive exposure. Data from Bandim suggest that this may lower mortality even among unvaccinated children who contract the disease.

These studies from Guinea-Bissau may also have consequences for our understanding of the dramatic decline in mortality from measles which occurred in the beginning of this century in the industrialised world. ${ }^{3}$ There is no specific evidence that this decline was due to improved nutrition. In contrast, it has recently been argued that change in the age at infection was a main factor in the decline in mortality from the disease in England and Wales during the early decades of this century. ${ }^{318}$ Reduced family size as a result of lower fertility presumably raised the age at infection, thereby leading to a fall in the case fatality ratio. ${ }^{3}$ Data on age at infection in England and Wales are not available, but it has been argued that the increasing age in deaths associated with measles in the first decades of this century indicates a higher age at infection in the community. ${ }^{318}$. The increase in age at infection, however, may not have been very great.

The data from Bandim illustrate a different process which may lead to a higher mean age among fatal cases of measles. Age at infection fell and there were more isolated cases, particularly among children below 2 years of age (table IV). The fall in mortality was also concentrated among children under 2, whereas mortality remained constant among older children (tables I, IV). This produced a trend towards a higher median age in deaths associated with measles. Hence the prevalence of children aged 5 and over among fatal cases of measles increased from 4\% (3/77) in 1979 to $13 \%(6 / 48)$ in $1980-4$ (table $I ; p=0.08$; Mantel-Haenszel $\chi^{2}=3 \cdot 3$ ). Furthermore, community studies and notifications from the turn of the century show that the proportion of all cases of measles that were in children under 3 was $32 \%$ (100/314) in Sunderland in $1885,{ }^{19} 33 \%$ (13 451/40 374) in Aberdeen in 1883-1902, ${ }^{20}$ and $23 \%(4572 / 19567)$ in Renfrewshire in 1893-1912. ${ }^{21}$ This differs little from later notifications from England and Wales generally in $1945^{3}$ and $1963^{22} 27 \%$ (118580/443755) and 30\% (15647/52 992) of cases, respectively, being in children under 3 . When measles was severe in the United Kingdom Picken noted that variations in mortality could not be explained by differences in age distribution. ${ }^{2}$

Whereas reduced family size in the industrialised world has tended to increase the age at infection, the effects have probably been countered by urbanisation and improved communications and child care services. Intensity of exposure has been found to be a risk factor for fatal measles in both England and Denmark. ${ }^{1923}$ The decline in mortality in the industrialised world may therefore have more to do with reduction in clustering of cases and intensity of exposure than with changes in the age at infection. Various factors are likely to have contributed to the reduction in clustering and intensity of exposure-for example, reduced family size, improved housing and child care services, the altered epidemiological patterns as a result of improved communications and urbanisation, and antiexposure measures such as isolation and prophylactic use of convalescent serum. 
Our study suggests that those sociocultural and epidemiological factors which help reduce clustering of cases and intensive exposure may help to reduce mortality from measles. Decline in deaths may occur irrespective of concurrent improvements in nutritional state, hygienic conditions, and therapeutic practices or changes in the age composition of patients.

Data from Guinea-Bissau were collected in a study jointly organised by the Ministry of Health, Guinea-Bissau, and the Swedish Agency for Research Cooperation with Developing Countries (SAREC). The study was supported by the Danish Council for Development Research, Danish Medical Research Council, and Danish Social Science Research Council. Special thanks are due to Drs M Boal and P Medina, Secretary Generals, Ministry of Health, Guinea-Bissau, for their interest. We are indebted to Carolina Barbosa, Matarina Có, Manuel Fernandes, Armando Gomes, Joaquim Gomes, Mariano Soares da Gama, Francisco Indi, Joana Lopes, Eugenio Pereira, Angelina da Silva, and Fatima Turé, who helped with the collection of data.

\section{References}

1 Walsh JA. Selective primary health care: strategies for control of disease in the developing world. IV. Measles. Rev Infect Dis 1983;5:330-40.

2 Mayer J. Measles and the state of nutrition. Postgrad Med 1969;45:253-4.

3 Reves R. Declining fertility in England and Wales as a major cause of the twentieth century decline in mortality. The role of changing family size and age structure in infectious disease mortality in infancy. Am f Epidemiol 1985;122:112-26.
4 Aaby P, Bukh J, Lisse IM, Smits AJ. Measles mortality, state of nutrition, and family structure: a community study from Guinea-Bissau. $\mathcal{F}$ Infect Dis 1983;147:693-701.

5 Aaby P. Malnutrition and overcrowding-exposure in severe measles infection. A review of community studies. Rev Infect Dis (in press).

6 Aaby P, Bukh J, Lisse IM, Smits AJ. Overcrowding and intensive exposure as determinants of measles mortality. Am J Epidemiol 1984;120:49-63.

7 Aaby P, Bukh J, Lisse IM, et al. Determinants of measles mortality in a rural area of GuineaBissau: crowding, age, and malnutrition. F Trop Pediatr 1984;30:164-9.

8 Aaby P, Bukh J, Leerhøy J, Lisse IM, Mordhorst CH, Pedersen IR. Vaccinated children get milder measles infection: a community study from Guinea-Bissau. $\mathcal{F}$ Infect Dis 1986;154: $858-63$

9 Aaby P, Bukh J, Lisse IM, Smits AJ. Measles vaccination and reduction in child mortality: a community study from Guinea-Bissau. $\mathcal{I}$ Infect $1984 ; 8: 13-21$

10 Aaby $\mathrm{P}$, Bukh J, Hoff G, et al. High measles mortality in infancy related to intensity of exposure. I Pediatr 1986;109:40-4.

11 Dustin JP, Lavoipierre GJ, Dixon H, Keller W. Measurements of nutritional impact. Geneva: WHO, 1979.

12 Foldspang A, Juul S, Olsen J, Sabroe S. Epidemiologi. Copenhagen: Munksgaard, 1986:134 3 Morley D, Woodland M, Martin WJ. Measles in Nigerian children. I Hyg (Camb) 1963;61: $115-34$

14 Koster FT, Curlin GC, Aziz KMA, Haque A. Synergistic impact of measles and diarrhoea on nutrition and mortality in Bangladesh. Bull WHO 1981;59:901-8.

15 Bhaskaram P, Madhusudhan J, Radhakrishna RV, Reddy V. Immune responses in malnourished children with measles. F Trop Pediatr 1986;32:123-6.

16 Neiburg P, Dibley MJ. Risk factors for fatal measles infections. Int $\mathcal{F}$ Epidemiol 1985;15:309-11.

17 Davis R. Measles in the tropics and public health practice. Trans $R$ Soc Trop Med Hyg 1982;76:268-75.

18 Anonymous. Infant mortality and family structure [Editorial]. Lancet 1985;ii:650.

19 Aaby P, Bukh J, Lisse IM, Smits AJ. Severe measles in Sunderland, 1885: a European-African comparison of causes of severe infection. Int $\mathcal{F}$ Epidemiol 1986;15:101-7.

20 Wilson JG. Measles: its prevalence and mortality in Aberdeen. Public Health 1905;18:65-82.

21 Picken RMF. The epidemiology of measles in rural and residential area. Lancet 1921;i:1349-53.

22 Miller DL. The public health importance of measles in Britain today. Proceedings of the Royal Society of Medicine 1964;57:843-6.

23 Aaby P. Severe measles in Copenhagen, 1915-1925. Rev Infect Dis (in press).

(Accepted 23 December 1987)

\section{SHORT REPORTS}

\section{Delays in diagnosing and treating bladder cancer}

Wallace and Harris said over 20 years ago that most of the responsibility for the delay in diagnosing bladder cancer lay with the hospital service. ${ }^{1}$ I conducted this study to see whether delays still exist and, if so, where they occur.

\section{Patients, methods, and results}

All patients in whom a new bladder cancer had been found were interviewed to establish the date of their first symptom and the date of their first visit to their general practitioner for that symptom. The dates of outpatient appointments and cystoscopy were also recorded. Consultants used different methods in managing patients, and as the numbers were skewed the values given are medians (and ranges).

One hundred patients were interviewed, of whom 70 were men. The patients' mean age was $67 \cdot 7($ SEM $1 \cdot 27$ ) years (range 29-92). Painless haematuria was the presenting symptom in 67, painful haematuria in 18, "cystitis" in 12, and obstructive symptoms in three. Twenty of the patients were admitted as emergencies.

The median total delay in diagnosis was 18 (1-316) weeks; the median delay by patients was 1 (1-263) week, by general practitioners 2 (1-308) weeks, and by hospitals 8 (1-226) weeks. When the 20 emergency admissions were excluded from the hospital figures the delay was $9(2-226)$ weeks. The table shows the delays by sex, age, and presenting symptom.

Patients had to wait $18(1-97)$ days for their first appointment at the outpatien department. Half of them were given follow up appointments, for which they waited 26 (14-82) days. The waiting time for operations was 28 (2-177) days. The time waited for the first appointment did not vary except with age: patients aged over 80 were seen in $8(1-44)$ days whereas those aged under 50 were seen in 19 (15-63) days.

\section{Comment}

The patients saw their general practitioners quickly after discovering their first symptoms. This pattern has not changed over 20 years ${ }^{12}$ and is similar to that in Denmark. ${ }^{3}$ The proportion of patients presenting with painless haematuria has fallen from that of $80 \%$ reported in Bristol and London 20 years ago. ${ }^{12}$ Why more patients are presenting with confusing symptoms is
Delays in diagnosis in weeks by age, sex, and presenting symptoms. Values are medians (ranges)

\begin{tabular}{llllc}
\hline & \multicolumn{4}{c}{ Delay } \\
\cline { 2 - 5 } & Overall & $\begin{array}{c}\text { By } \\
\text { patients }\end{array}$ & $\begin{array}{c}\text { By general } \\
\text { practitioners }\end{array}$ & $\begin{array}{c}\text { By } \\
\text { hospitals }\end{array}$ \\
\hline Age (years) & & & & \\
$<50(\mathrm{n}=9)$ & $22(5-164)$ & $7(1-52)$ & $8(1-154)$ & $7(2-17)$ \\
$50-65(\mathrm{n}=28)$ & $18(3-267)$ & $1(1-263)$ & $4(1-178)$ & $9(2-88)$ \\
$66-80(\mathrm{n}=44)$ & $17(4-316)$ & $2(1-113)$ & $3(1-308)$ & $10(2-226)$ \\
$>80(\mathrm{n}=19)$ & $17(2-83)$ & $1(1-82)$ & $2(1-52)$ & $8(2-15)$ \\
Sex: & $18(2-316)$ & $2(1-263)$ & $2(1-308)$ & $10(2-226)$ \\
$\quad$ Male $(\mathrm{n}=70)$ & $16(2-188)$ & $1(1-113)$ & $4(1-154)$ & $7(2-133)$ \\
Female $(\mathrm{n}=30)$ & & & & $7(1-308)$ \\
Presenting symptom: & $17(2-316)$ & $2(1-263)$ & $7(2-226)$ \\
$\quad$ Painless haematuria $(\mathrm{n}=67)$ & $23(2-133)$ & $2(1-52)$ & $4(1-52)$ & $10(2-133)$ \\
Other $(\mathrm{n}=33)$ & & & & \\
\hline
\end{tabular}

^ Excluding emergency admissions.

unclear. Patients under 50 delayed longer than older patients, for which no discernible reason could be found.

General practitioners responded well to patients presenting with painless haematuria: three quarters of them referred such patients within a month. This is an improvement over the past 20 years. ${ }^{1}$ General practitioners tended, however, to delay longer in referring patients under 50 .

The time taken by the hospital service was disappointing. Wallace and Harris said that the median delay in the hospital service was around seven weeks and this has now increased to nine, partly because of differences in patterns of referral. The delay in Denmark, however, was three weeks. ${ }^{3}$ Although disagreement exists about whether a delay in treatment alters the prognosis, ${ }^{13}$ any delay is obviously worrying for patients and their relatives. I could not easily identify any particular factor causing this delay. One reason is probably inflexibility. As more patients are seen each year clinics and operating lists become fully booked sooner, leaving little opportunity to add urgent cases. Various administrative errors conspired to delay admissions. In addition, one of the consultants ran a clinic for haematuria in these hospitals, the effect of which was to reduce the delay till the first appointment, though it had no effect on the overall delay.

This study highlighted the need for audit of routine hospital practice; subsequently efforts were made to improve the service. 